\title{
Dialectical Relevance and Dialogical Context in Walton's Pragmatic Theory
}

\author{
FABRIZIO MACAGNO
}

\author{
Università Cattolica del Sacro Cuore \\ Department of Linguistics \\ Via Necchi 5 \\ 20100 Milano \\ Italy \\ fabriziomacagno@hotmail.com
}

\begin{abstract}
The notions of types of dialogue and dialectical relevance are central themes in Walton's work and the grounds for a dialectical approach to many fallacies. After outlining the dialogue models constituting the background of Walton's account, this article presents the concepts of dialectical relevance and dialogue shifts in their application to biased argumentation, fallacious moves, and illicit argumentative strategies. Showing the different dialectical proposals Walton advanced in several studies on argumentation as a development of a dialogical system, it has proved possible to highlight the fundamental aspects of his theory in a comprehensive model of communication and interaction.
\end{abstract}

Resumé: La notion de type de dialogue et de pertinence dialectique sont des thèmes fondamentaux dans l'œuvre de Walton et dans les fondements d'une approche dialectique sur plusieurs sophismes. Premièrement on dessine des contours des modèles de dialogue qui consti-tuent l'arrière-plan de l'approche de Walton. Deuxièmement, on présente les concepts de pertinence dialectique et de faux-fuyants dialogiques dans leurs applications à l'argumentation biaisée, les manœuvres fallacieuses, et les stratégies argumentatives interdites. On montre que les différentes propositions avancées par Walton dans ces études d'argumentation forment un système dialogique, et ainsi on prouve qu'il est possible de mettre en lumière les aspects fondamentaux de sa théorie dans un modèle compréhensif de la communication et de l'interaction.

Keywords: Relevance; Dialogue Shifts; Communication Context; Implicit Commitments; Walton's Dialectical Theory.

\section{Introduction}

The theory of dialogue games is one of the more influential theoretical proposals of Walton's studies. It constitutes the background of the model of dialogue types, upon which the analysis of many fallacies is grounded. This formal approach to dialogue, however, has been revolutionized in Walton's works, which transformed a formal dialogue theory in a much richer kind of dialectical framework. The dialogue-game theory is in fact developed into a dialectical model that takes into account essential 
factors of human communication, such as interlocutors, common ground, and context. The theory of dialogue types becomes, thereby, a unique proposal making it possible to open a dialogue between linguistic approaches to communication and argumentation studies. Dialectical relevance is the key notion necessary to understand the evolution of Walton's dialectical theory from the first formal models of dialogue, characterized by sets of precise, but not necessarily realistic dialectical rules, to the communication model developed in the last advances of his pragmatic approach. This theme, whose crucial importance has been recognized in other recent argumentation theories (Van Eemeren and Houtlosser, 2005) and recently developed in computing (Wells and Reed, 2006) and law (Walton 2006, Prakken 2001), runs like a red thread into Walton's studies, connecting his theory of fallacies with the topics of burden of proof, interpersonal communication, argument schemes and argument evaluation. These latter themes, in their turn, represent essential steps in the development of Walton's dialogue theory. The analysis of the evolution of dialectical relevance offers, for this reason, a unique and deep perspective on the most important phases of Walton's works.

After an historical overview on dialogue-games theories, the concept of dialectical relevance will be introduced, explaining its role in Walton's model of dialogue types, and showing how it has been applied to the pragmatic approach to fallacies. The evolution of the studies on some sophisms such as ad hominem or ad baculum, conceived in the latter works as irrelevant dialogical moves, and the applications of the dialogue-types model to legal contexts and different types of dialogical situations open up new perspectives on Walton's conception of communication. In particular, if we examine Walton's latter works on dialogue theory, we can notice how the dialogical framework, originally constituted by dialectical rules and abstract entities called "agents" or "participants", is expanded to include factors such as the interlocutors, conceived as individuals belonging to a given culture, their role, and their position in the interaction. Starting from these premises, we can develop a dialogue model grounded on the concept of "context of dialogue". In this model, are not only participants' goals included, but also their relationship and common ground become essential components. On such a basis it is possible to connect argumentation and dialectical studies to a pragma-linguistic foundation, making dialectical relevance the keystone for inquiring into the dialogical aspects of communication.

\section{Dialogical Relevance in Theory of Dialogues}

This section is articulated in two interrelated topics, the theory of dialogue types and the theory of dialectical relevance. The historical outline of the theory of dialogues below is aimed at explaining what a dialogue is in argumentation, what its role is, and how it evolved in the first phases of Walton's new dialectic. In Walton (1984) the formal models of dialogue developed from the theory of Hamblin (1970) and 
Barth and Krabbe (1982) are integrated with the notion of implicit commitments, thereby linking the systems of turn-taking and commitment rules to the communication aspect of shared and common knowledge. Following Hintikka's account of question-answer argumentation, Walton further introduced the model of profiles of dialogue, in which a dialectical move is evaluated in relation to what might be linguistically called its "context". The participants' goals and the communicative situation were taken into consideration in Walton's subsequent account of "dialogue types", namely an analysis of dialogue based on different kinds of the participants' communication purposes. At last, the evolution of the theory of dialectical relevance brought Walton's dialogue types to move towards a more linguistic perspective on dialectics. My purpose is to focus on a specific relation of dialectical relevance between a speech act (or, better, conversational move) and the type of dialogue it occurs in, which will be called "dialogical relevance".

\subsection{The Development of Formal Dialectical Games into Dialogue Theory}

Walton's account of profiles of dialogues is original, but evolved from Hamblin's (1970), Hintikka's (1979), and Barth and Krabbe's (1982) formal theories of argumentative dialogue. Generally, in these approaches a dialogue is made up of a set of participants who perform verbal moves according to certain rules, and these rules determine turntaking and win-loss conditions. The formal models of dialogue can be compared to the medieval obligation games, which in turn evolved from their ancient predecessors (see Walton, 1984). From Hamblin's presentation of formal dialogues in Fallacies to Walton's theory of dialogue types in The New Dialectic, dialogue game theory has evolved putting more emphasis on some recently studied factors of communication, such as the notion of shared knowledge, and the interlocutors' goals. Walton's account of dialogical relevance can be understood in the framework of this evolution from abstract dialogue theories to dialogical moves conceived as acts of human communication.

In Hamblin's view, dialogues are seen as formal structures used to systematically analyze fallacies in relation to dialogical criteria of commitment and acceptability, in addition to logical rules. A game of dialogue, on this view, is constituted by two participants each having his own commitment store, that is, a set of propositions that a participant has gone on record as accepting. Commitments stores contain statementtokens that do not have to be consistent. Inconsistent commitments are, however, open to challenge. In a game, locutions can be of the type 'Statement S', 'No commitment S', 'Why S?', 'Question S', and 'Resolve S'. They are regulated by syntactical rules, which provide criteria for turn taking and locution succession order. Moreover, a set of norms are given, which regulate the effects of a locution on the commitment stores. For instance, a statement ' $S$ ' places the propositions $\mathrm{S}$ in the speaker's commitment store, under certain conditions. The rules governing the relation between locutions and commitments are defined in 
different dialogue games (Hamblin 1970, pp. 254-255). The pioneering perspective opened up by Hamblin about formal models of dialogue and the plurality of dialogue games was further developed by Barth and Krabbe.

Barth and Krabbe's formal dialectical theory, presented in (Barth and Krabbe 1982) was influenced by the work of Lorenz and Lorenzen and their proposal of founding logic on dialectical principles. On Lorenz and Lorenzen's view, basic logical principles, such as meaning and validity, could be grounded on dialectics and translated into win-loss rules. From this background, Barth and Krabbe developed their proposal of replacing the notion of truth with the dialectical principles of accepting a point of view, whereas the notion of validity is dialectically interpreted as "having winning strategy" in a dialogue (see Barth and Krabbe 1982, pp. 315; 54). In their theory, logical axioms (such as the non-contradiction principle) were translated into dialectical norms (for instance, a win-loss rule) which delineate different types of dialogues, that is, formal ${ }_{3}$ systems, or, rather, systems of rules for verbal resolution of conflicts of opinions (1982, p. 19). In Barth and Krabbe's theory, a dialogue is analyzed as a succession of moves (that can be translated into propositional logic) having a pragmatic character, that is, an effect on the dialogue. On their view, different dialectical norms characterize different dialogue types.

The fundamental change of perspective, Hamblin's and Barth and Krabbe's theories brought about, is basically grounded on the use of the notion of commitment in dialogue and fallacies analysis. Commitments are propositions an interlocutor is obliged to defend in case they are challenged by the other party, and that a party cannot retract except under special conditions. Propositions are therefore characterized by a dialectical principle and are not conceived as truth-bearers. For this reason, commitments constitute a dialectical principle much wider than the logical idea of truth, and the epistemic notion of knowledge (see Walton and Macagno 2005). The principle of evaluating the acceptability of a move in relation to commitment rules lays beneath the foundation and evolution of dialogue models.

Noticeable change of perspective was introduced by Hintikka's studies on information-seeking dialogues (1979). In his logical dialogue models, Hintikka analyzed a fundamental aspect of dialogic exchange, namely the process of question and answer. A question, on Hintikka's view, can in fact contain presuppositions, namely propositions the hearer is committed to even though he answers negatively. For instance, we can analyze the following case (Walton 1984, p. 246):

(1) Have you stopped abusing your spouse?

The question above leaves open two possible answers: 'yes' or 'no'. In both cases, the answerer is committed to a binary paradigm of choices, namely 'I stopped abusing my spouse' and 'I did not stop abusing my spouse' (for the concept of paradigm of choices and types of paradigms, see Gatti 2000). As the question is asked, the presupposition of the 
question, namely that 'the hearer used to abuse his spouse', is inserted in the interlocutor's commitment store. The study of questions of this sort introduced the notion of implicit knowledge into dialogue theory. Theories must consider not only propositions explicitly asserted, but also propositions which the interlocutors take for granted because (supposedly) commonly known. Common knowledge, we can notice, is in fact closely related to the notion of presupposition (see Rigotti, to appear, p. 10; Rigotti, 2006, p. 14). If we consider presupposition the essential requirement for meaningfulness of a textual sequence (Seuren, 2000), and regard meaningfulness as an inter-subjective notion, the possibility of a sequence to be meaningful for the interlocutor lies on his sharing the sequence presuppositions. For instance, the following sequence can be meaningfully interpreted only if its presuppositions are part of the common knowledge the interpreter is acquainted with:

(2) Bob redecorated his house yesterday

The utterer of this textual sequence presupposes that his interlocutor knows who Bob is, that Bob has a house, and that he already decorated it in the past. If some piece of this information is not shared by the interlocutor, he cannot retrieve the meaning of the sequence, which is thereby meaningless to him.

Walton (1984, p. 247) developed Hintikka's proposal by taking into account the implicit aspect of communication. For this purpose, he conceived the idea of dark-side commitments, namely propositions that there is no need to assert because already shared. These propositions are not part of the current dialogue game, but are taken for granted, and can play an active part in the verbal exchange after being transferred to the light (or rather, explicit) side of the dialogue. For instance, we can imagine using (1), reported above, in a dialogue in which the following rule applies (Walton 1984, p. 258):

If a player states 'No commitment $\mathrm{S}$ ' and $\mathrm{S}$ is included in the dark side of his commitment-store, then $\mathrm{S}$ is immediately transferred into the light side of that player's commitment-store.

The dialogue characterized by this rule, in which (1) occurs as a dialogue move could be represented in the following diagram. Participants' moves (labelled as White and Black) are indicated together with their dark-side (DSC) and light-side (LSC) commitment stores: 


\begin{tabular}{|l|l|l|l|l|l|}
\hline White's DSC & White's LSC & \multicolumn{1}{|c|}{ WHTE } & BLACK & Black's LSC & Black's DSC \\
\hline $\begin{array}{l}\text { 1W. Black } \\
\text { abused his } \\
\text { spouse }\end{array}$ & $\begin{array}{l}\text { aW. White } \\
\text { does not know } \\
\text { the answer }\end{array}$ & $\begin{array}{l}\text { Have you stopped } \\
\text { abusing your } \\
\text { spouse? }\end{array}$ & & $\begin{array}{l}\text { 1B. Black } \\
\text { abused his } \\
\text { spouse }\end{array}$ \\
\hline $\begin{array}{l}\text { [1 W is moved } \\
\text { to LSC] }\end{array}$ & $\begin{array}{l}\text { bB.Black } \\
\text { abued his } \\
\text { spouse. }\end{array}$ & $\begin{array}{l}\text { No commitment } \\
\text { to "Black } \\
\text { abused his } \\
\text { souse". }\end{array}$ & & [1B. is deleted $]$ \\
\hline & & $\begin{array}{l}\text { You abused your } \\
\text { spouse because... }\end{array}$ & & & \\
\hline
\end{tabular}

Figure 1: Dark-side and Light-side commitments in Walton's dialogue theory

By asserting "No commitment to "Black abused his spouse", Blacks retracts his dark-side commitment to the quoted proposition (1B), and moves White's dark-side commitment to the same proposition (1W) from dark to light-side (bB). After this move, White has to support the proposition $b B$, if he wants it to be accepted. In this interpretation of Walton's theory, we can notice how common knowledge can be represented in a dialogue game as a set of dark-side commitments.

\subsection{Context, Agents and Goals in Walton's Dialogue Theory}

Walton's approach to dialogue theory revolutionized the perspective opened up by previous works in two crucial respects. First, the study of different possible types of dialogue and dialogical rules was applied to the examination of fallacies. Second, the analysis of different possible dialogue games was developed by integrating the concept of context and participants' goals as basic principles of dialogue classification and characterization. Starting from the integration of context and goals into dialectical games, Walton invented and successfully deployed the basic concepts of profile of dialogue and type of dialogue (for the origins of the notion of 'profile of dialogue' and its applications to other theories, see Krabbe 1999; 2001).

In Logical Dialogue Games and Fallacies (1984), Walton analyzed the ad hominem fallacy and other fallacies from the perspective of rules of dialogue. A particular type of ad hominem fallacy, that is the circumstantial ad hominem, consists in an attack on an interlocutor's inconsistency of commitments deriving from his words and his actions. We can explain this fallacy using the following argument (Walton 1996a, p. 58):

Parent: There is strong evidence of a link between smoking and chronic obstructive lung disease. Smoking is also associated with many other serious disorders. Smoking is unhealthy. So you should not smoke.

Child: But you smoke yourself. So much for your argument against smoking.

In this example, the parent's explicit commitments (smoking is unhealthy; smoking is not desirable...) conflict with the commitment 
which can be drawn from his behaviour, namely his smoking. The pragmatic inconsistency between words and actions, we can notice, is grounded on the Aristotelian principles of decision-making, which can be described as the choice of what is or appears to be desirable to the agent (Nicomachean Ethics III, 4, 1113a15). In this example, the father commits himself to the proposition 'smoking is bad', but from his behaviour it is possible to understand that he is implicitly committed to the contrary position, namely 'smoking is desirable'.

As seen in the models presented above, one of the ideals of a defensible commitment store is that of internal consistency, which we can summarize in the principle establishing that 'a commitment store containing contradictory or incompatible propositions is open to challenge'. Applying dialogue game theory to the fallacy evaluation, Walton observed that the acceptability or the fallaciousness of an ad hominem attack depends on the rules of the dialogue the participants are engaged in (Walton 1984, p. 279). However, in certain more restrictive models of dialogue, an inconsistency in commitments virtually leads to an immediate loss of the game for the criticized participant, unless he repairs the fault. In other dialogue games, the respondent has a better chance to resolve or explain the inconsistency. We can explain this concept using examples of real dialogue settings. For instance, the argument "you do not practice what you preach; therefore your argument is worthless", used in the dialogue above can prove extremely effective for refuting the speaker's position if employed, for instance, in persuasion dialogue between a promoter of no-smoking campaigns and a smoker. On the contrary, the same argument would be much less effective if the speaker were involved in a negotiation dialogue with a tobacco company. In other words, we can observe that the effects, and therefore the strength of the ad hominem argument, are dependent on the precise rules of the dialogue type in which the interlocutors take part.

In the successive development of Walton's theory, are commitments not only regarded as relative to the consistency of an interlocutor's commitment store, but are also analyzed in relation to the co-text, or rather the textual elements, such as the previous assertions, surrounding the move taken into consideration. Commitments, on this view, impose some restrictions on the possible moves that can be made in the course of a dialogue. This fundamental aspect of commitments can be understood analyzing the criteria which form the basis of the definition of a "dialogue-type". In a profile of dialogue, a dialogue is not seen anymore as a fully described formal game with all its dialectical rules. In a profile of dialogue, a move is described only in relation to the commitments deriving from prior moves, which in their turn characterize the possibility of making certain subsequent moves in a reasoned dialogue. In this new dialectical model, not only must a move respect dialectical norms, but also follow an order established on the basis of its co-text and previous commitments. This new account of dialogue can be applied to the analysis of the fallacy of many-questions examined by Hintikka (Walton 1989a, p. 68): 


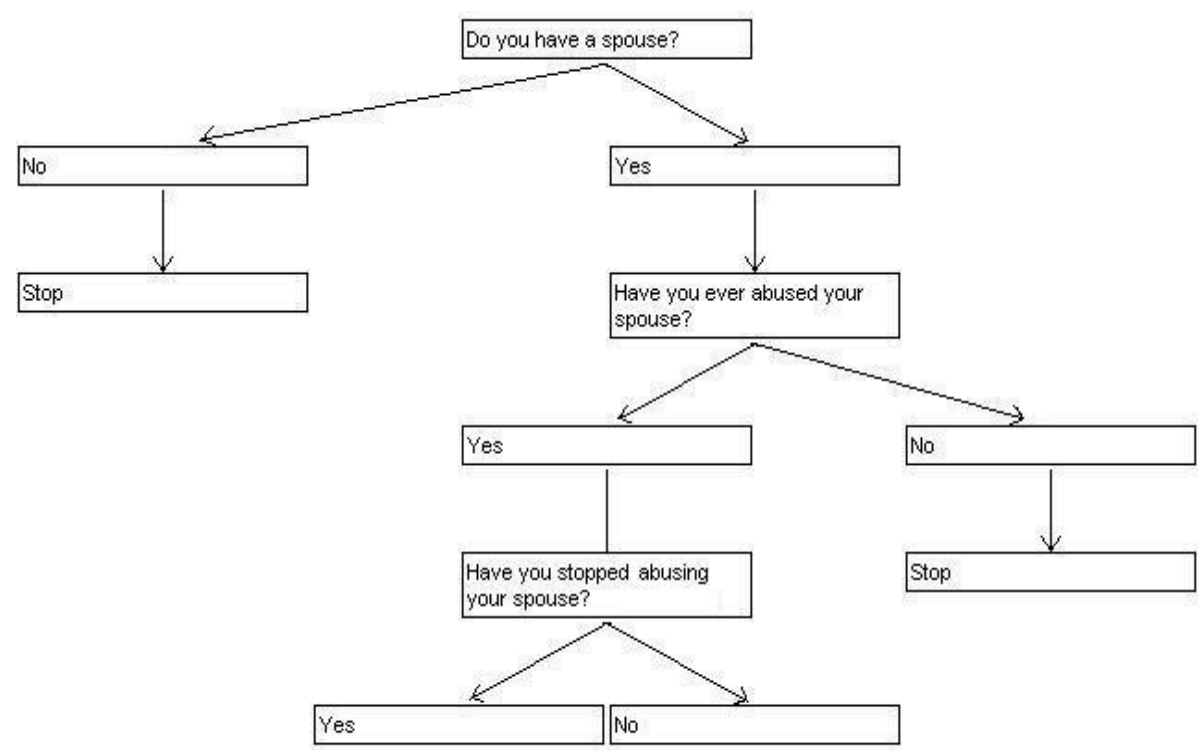

Figure 2: Profile of dialogue for the analysis of the fallacy of many questions

We can observe that in this model, the ideal sequence of moves represents the sequence required in order for a move to be adequate. A move can be made when what we can call its presuppositions are grounded on the commitments created in the previous moves.

The next crucial step in the evolution of a theory of dialogue is an analysis of dialogues based on the participants' purposes and communicative situation. The interlocutors may be, for instance, in a situation of conflict of opinion, or conflict of interests; their purpose might be persuading the other party, or getting what they most want. Given this pluralistic approach, instead of delineating a unique profile of dialogue, Walton (1989, later developed in Walton and Krabbe 1995) put forward the well-known classification of six basic dialogue types. These dialogue types constitute normative models for the conduct of dialogical conversations (Walton 1998): 
110 Fabrizio Macagno

\begin{tabular}{|l|l|l|l|}
\hline $\begin{array}{l}\text { TYPE OF } \\
\text { DIALOGUE }\end{array}$ & $\begin{array}{l}\text { INITIAL } \\
\text { SITUATION }\end{array}$ & $\begin{array}{l}\text { PARTICIPANT'S } \\
\text { GOAL }\end{array}$ & $\begin{array}{l}\text { GOAL OF } \\
\text { DIALOGUE }\end{array}$ \\
\hline PERSUASION & $\begin{array}{l}\text { Conflict of } \\
\text { opinions }\end{array}$ & $\begin{array}{l}\text { Persuade the } \\
\text { party }\end{array}$ & $\begin{array}{l}\text { Resolve or clarify } \\
\text { issue }\end{array}$ \\
\hline INQUIRY & $\begin{array}{l}\text { Need to have } \\
\text { proof }\end{array}$ & $\begin{array}{l}\text { Find and verify } \\
\text { evidence }\end{array}$ & $\begin{array}{l}\text { Prove(disprove) } \\
\text { hypotheses }\end{array}$ \\
\hline NEGOTIATION & $\begin{array}{l}\text { Conflict of } \\
\text { interests }\end{array}$ & $\begin{array}{l}\text { Get what you } \\
\text { want most }\end{array}$ & $\begin{array}{l}\text { Reasonable } \\
\text { settlement that } \\
\text { both can live with }\end{array}$ \\
\hline $\begin{array}{l}\text { INFORMATION- } \\
\text { SEEKING }\end{array}$ & $\begin{array}{l}\text { Need of } \\
\text { information }\end{array}$ & $\begin{array}{l}\text { Acquire or give } \\
\text { information }\end{array}$ & $\begin{array}{l}\text { Exchange of } \\
\text { information }\end{array}$ \\
\hline DELIBERATION & $\begin{array}{l}\text { Dilemma or } \\
\text { personal choice }\end{array}$ & $\begin{array}{l}\text { Co-ordinate goals } \\
\text { and actions }\end{array}$ & $\begin{array}{l}\text { Decide the best } \\
\text { available course } \\
\text { of action }\end{array}$ \\
\hline ERISTIC & Personal conflict & $\begin{array}{l}\text { Verbally hit out at } \\
\text { opponent }\end{array}$ & $\begin{array}{l}\text { Reveal deeper } \\
\text { basis of conflict }\end{array}$ \\
\hline
\end{tabular}

Figure 3: Dialogue types

This typology can be considered a broad classification of contexts grounded on the initial situation, the participants' goals, and the purpose of the dialogue the interlocutors are engaged in. The criteria for identifying a dialogue type are based on the relationship between interlocutors and on the basis of the communicative event.

The dialogue types are basic models of any dialogical interaction, and constitute the foundation for classifying the possible kinds of conversation. For example, political discourse, debate, or, at the extremes, propaganda, can be modelled as mixed dialogues (see Walton and Krabbe, 1995, Walton 2006b; Walton 2003a), that is dialogues in which the participants have several different purposes. For instance, in a political debate, the participants want to persuade others that they are right, but at the same time they want their opponent to look bad.

\subsection{Relevance in Dialogue}

Introducing different dialogue games into the overall theory of argumentation provides new criteria for evaluating the acceptability of a move. As seen above, in a theory grounded upon different possible types of dialogues with different rules, such as, for instance, in Barth and Krabbe's proposal (1982), the fallaciousness of an argument should be assessed relative only to the norms constituting the dialogue. In Walton's account, the context of dialogue provides instead a new parameter of evaluation, enlarging the notion of relevance treated in the contemporary argumentation theories so as to include the whole communicative setting.

An important survey on relevance in argumentation, summarizing the most important views on the subject, has been presented in (Walton 1989, p. 78-81). Walton distinguished four kinds of relevance in a dialogue: global, local, subject-matter, and probative. In an argumentative discussion, each participant has a position to defend, challenge, or question. A position is related to an issue: the proponent, in a dialogue, expresses an opinion on a subject, while the interlocutor 
opposes either by expressing doubts, or by proposing a contrary position. The participants share the common goal of resolving this disagreement, and their chain of argumentation is aimed at this purpose. Global relevance can be explained as the overall direction of the arguments in the discussion. Arguments must move forward to establishing or objecting the thesis, and thereby must be related to the issue. On the other hand, local relevance is relative to single moves in the argumentation process. For instance, an answer is locally relevant if it is related to the question asked and fulfils its role in the communicative sequence. There are two ways a communicative move can be globally or locally relevant for the dialogue: it can be subject-matter (or topically, see Walton 2006a) relevant, or probatively relevant. A proposition can be subject-relevant to another if the subject-matter of the former overlaps with the subjectmatter of the latter. For instance, we can consider the following cases (Walton 2006a):

1) Bob ate two bananas

2) Bananas are yellow

The two propositions overlap relative to the subject matter. A premise can be considered probatively relevant for the conclusion if it plays a part in proving or disproving the thesis. However, in the case above, it cannot be said that (1) is used to prove or disprove (2). The different types of relevance in argumentation can be represented in the following diagram:

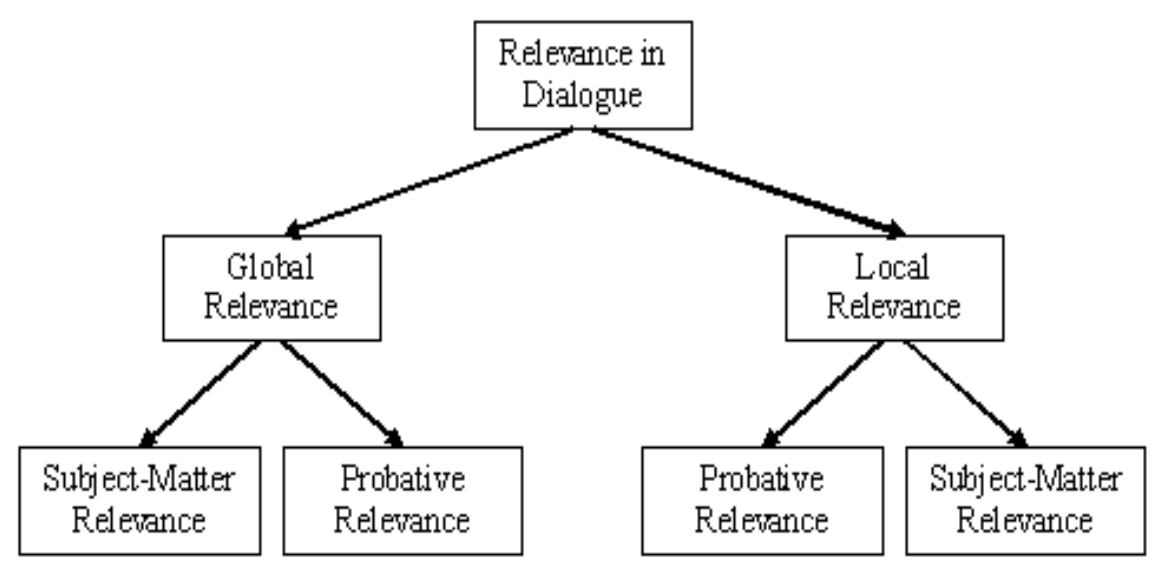

Figure 4: Relevance in dialogue

This general classification of relevance, however, does not represent the relation of dependence between the different types of relevance in a dialogue. In fact, we can compare the example above with the following case:

2') Bob has never eaten fruit before. Bob is changing his diet. 


\section{Fabrizio Macagno}

Whereas (1) is locally subject-matter relevant but probatively irrelevant to (2), (1) is both subject-matter and probatively relevant to (2'). Moreover, we can imagine the propositions as dialogical moves in a dialogue. We can notice that the couple (1)-(2') can constitute an argument relevant to a possible issue of a dialogue, which might be, for instance, related to Bob's behaviour, whereas the couple (1)-(2) cannot be relevant at a global level because it does not represent an argument at all. Moreover, the couple (1)-(2') can be globally relevant if placed in a dialogue in which they are subject-matter related to the issue. The same couple would be globally irrelevant in a dialogue about the economic growth of Germany. For this reason, we can notice how global relevance is strictly dependant on local relevance. Not only, in order for the requisite of global relevance to be satisfied, must the single sequences constituting the dialogue be internally relevant (that is, they must be made up of moves relevant to each other), but the sequences themselves must also be relevant to each other. Moreover, global probative relevance presupposes global subject-matter relevance, and local subject-matter relevance is the fundamental requisite of local probative relevance. In fact, in order for a thesis to be proved, the sequences of dialogue must be related to the issue; at a local level, the moves constituting the sequences cannot prove their conclusion if are irrelevant to each other. We can diagram the relationships between the types of relevance as follows:

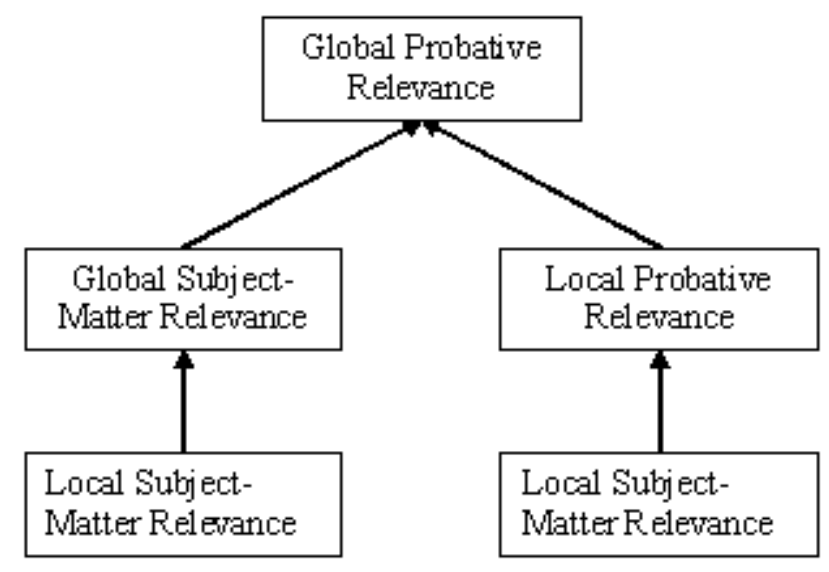

Figure 5: Relationship between the types of relevance

The study of relevance in argumentation was deepened in the pragmadialectical theory. Van Eemeren and Grootendorst analyzed relevance in relation to the stages of the critical discussion and speech-act conditions. A speech act, on this perspective (for a summary, see van Eemeren and Grootendorst 2004, p. 78), is relevant if the sequel to the earlier speech acts is appropriate in the communicative situation in which it is performed. In the ideal model of a Critical Discussion, the distinction between four stages of dialogue, characterized by specific goals, allows one to evaluate the relevance of a speech act relative to the goal of the discussion stage in which it occurs. Some speech acts are suited to 
achieve a particular interactional goal. For instance, assertives are usually used to advance a standpoint in the confrontation stage, while directives are normally used to challenge or defend a position in the opening stage (p. 68). The pragma-dialectical notion of relevance was integrated into Walton's model of probative relevance (see Walton 1998, p. 110; 2006, p. 184). Probative relevance, in this perspective, is articulated into a more flexible pragmatic concept of relevance, connecting the global function of a dialogue with the communicative roles of the dialogue stages. In this view, the concept of relevance is widened to examine not only logical or semantic relations between propositions, but also communicative roles of dialogue moves.

These studies on the concept of relevance are useful to understand the role of Walton's proposal. Walton extended relevance from a pragmatic to a dialogical notion. Relevance, as noted in (Walton, 1998, p. 110), depends on the type of dialogue taken into consideration. The pragmadialectical account of relevance was broadened, on this view, to include not only the purpose of the dialogue stage, but the overall purpose of the type of dialogue. The purpose of a critical discussion, Walton observes, is inherently different from the goal of a negotiation. In a persuasion dialogue, the two parties have to prove a point and resolve a conflict of opinion. In a negotiation, an argument is relevant if it constitutes a step towards resolving a conflict of interests by the agreement of both parties. For this reason, determinate arguments, which cannot be relevant to prove the acceptability of a proposition, can be relevant to lead the other party to come to an agreement. We might consider for instance the following patterns of arguments (from Walton 1999, pp. 89-90; 1995, p. 157):

\begin{tabular}{|c|c|}
\hline & Practical Reasoning \\
\hline MAJOR PREMISE: & I have a goal $G$. \\
\hline MINOR PREMISE & $\begin{array}{l}\text { Carrying out this action } A \text { is the } \\
\text { best means to realize } G \text {. }\end{array}$ \\
\hline CONCLUSION: & $\begin{array}{l}\text { Therefore, I ought (practically speaking } \\
\text { to carry out this action } A \text {. }\end{array}$ \\
\hline PREMISE 1 & $\begin{array}{l}\text { Argument from Threat } \\
\text { If you bring about } A \text {, some cited } \\
\text { bad consequences, } B \text {, will follow. }\end{array}$ \\
\hline PREMISE 2 & I am in position to bring about $B$. \\
\hline PREMISE 3 & $\begin{array}{l}\text { I hereby assert that in fact I will see to it } \\
\text { that } B \text { occurs if you bring about } A \text {. }\end{array}$ \\
\hline CONCLUSION & Therefore you had better not bring about \\
\hline
\end{tabular}

These kinds of reasoning are usually not relevant in dialogues of the kind where the truth or the acceptability of a proposition is at stake. However, they are acceptable argumentative moves in a context in which a deliberation or negotiation is underway. Indirect threat, according to Walton (1998, p. 114) is usually seen as appropriate and relevant in 


\section{Fabrizio Macagno}

negotiation, while irrelevant and fallacious in a persuasion dialogue. Dialogical relevance, then, is based on the criterion of dialogical goal and thereby on interlocutors' communicative situation.

To summarize, in this section we described relevance in dialogue showing its evolution in the various theoretical developments of dialogue theory. The idea of dialogical relevance can be found in some first abstract models of dialogue games, and is developed in argumentation theory within the frame of types of dialogue. Relevance in dialogue is in this fashion explained both by reference to its theoretical components and its background. In the following section we will use the notion of dialogical relevance for explaining the relation between licit and illicit dialogue shifts. In this fashion, we will apply Walton's insights on relevance to a perspective on dialogue more focussed on the interlocutors' purposes, which constitutes the first step towards framing Walton's dialogue theory within a wider dialogical framework.

\section{Relevance in a Dialogue Context}

The criterion of dialogical relevance presented in the section above is the basis of Walton's new approach to argument evaluation. Most everyday conversational arguments, in Walton's perspective, are defeasible lines of proof, that is, they are grounded on incomplete knowledge and thereby can reach only a provisional conclusion. An argument can prove that a conclusion is true or false only presumptively, that is, subject to new contradictory evidence that might come in. The notion of absolute truth is not helpful to explain everyday argumentation, in which the knowledge on which a line of reasoning is based generally tends to be subject to reevaluation as new knowledge comes in. Moreover, in everyday conversation many different patterns of reasoning are used. The purpose of some of them is to prove the acceptability of a proposition, while other schemes are aimed at attacking the credibility of the interlocutor, or leading him to make decisions on different grounds.

The analysis of arguments in a context of dialogue makes argument evaluation a pluralistic and relative notion. An argument can be considered strong and acceptable in a certain context of dialogue, while in another context only weak or irrelevant to proving the conclusion. The strength of an argument, in other words, is dialogue-dependent. While the first studies of fallacies were basically grounded on the purpose of a dialogue and rules of retraction, in the latter studies other factors become included in what we can call (developing Walton's proposals) "dialogue context". We can notice, for instance, that the interlocutors' goals and their shared knowledge are essential elements in Walton's analysis of bias, dialogue embeddings, and illicit dialogue shifts. Developing the perspectives opened up by these theoretical steps towards a wider notion of dialogue, we can describe dialogue not only as a succession of moves respecting or disregarding dialectical rules, but as a communicative event in which two real agents, with their own goals and desires, interact. Relevance in dialogue becomes in this view the link between agents in 
communication and dialogue theory, connecting argumentation studies to pragma-linguistic theories. Presenting what dialogical relevance is, and the role it plays in Walton's latter works on dialogue embeddings, is the starting point for understanding the development we propose.

\subsection{Interactional Relevance: Interlocutors' Purposes in Dialogue Shifts}

Dialogues are not closed models. Their fundamental aspect is the purpose of the participants, and for this reason it is possible for one dialogue to be a step towards the fulfilment of the goal of another dialogue. Dialogues can be mixed when the goal of a dialogue type is relevant to the goal of the communicative exchange in which it is embedded. For instance, one of the most common cases of relevant shifts is from a decision making dialogue, whose purpose is to make a decision, to an information-seeking dialogue, which is aimed at retrieving information. The information collected in the embedded dialogue is used to decide about the issue. We can take into consideration the following cases (Norman et al. 2003, p. 40):

\section{Case 1}

Two agents have an intention to hang a picture. They are discussing how to do it. The first agent has the picture and a hammer, and knows that the second agent can get a nail. The first agent proposes hanging the picture provided the other agent will supply the nail.

In this example, the two agents are engaged in is a deliberation. They are discussing how to bring about an action, but in order to accomplish this task, they have to shift to a negotiation. The goal of the negotiation can be considered as a sub-goal of the main discussion. Negotiation, on the contrary, can shift to persuasion dialogue. Shifts of this kind are frequent when the participants agree that not only is the satisfaction of their own interests important in the dialogue, but also the reaching of a sensible decision. For this reason, they shift to a persuasion dialogue, in order to look at the evidence in a more objective way. Child custody negotiations can be clear examples of this typology of shift (see for instance Walton 1992, p. 139).

The most common embedding occurs when information is needed to accomplish the goal of a dialogue (for instance, see Walton, 1992, Norman et al. 2003, p. 40, Walton 2006a). For example let's take a legal case into consideration (Walton 1997, p. 159):

\section{Case 2}

The accused calls a psychiatrist as the next defense witness. Pursuant to court order the psychiatrist examined the complainant before the trial. Based on that examination, the psychiatrist is prepared to testify that the complainant suffers from a psychosis which produces sexual delusions that the complainant cannot distinguish form real events. In this variation of the hypothetical, the expert is prepared not only to 


\section{Fabrizio Macagno}

vouch for a general theory, such as the symptomatology for the psychosis, but also to apply the general theory to the specific facts of the complainant's case history to form an opinion about the complainant's credibility

The goal of the trial, which can be classified in its basic structure as a critical discussion, is to prove which side can prove its ultimate claim. In order for each side to fulfil its goal, information is needed, and in this case an expert is consulted. Since expert consultation dialogue is a species of information-seeking dialogue, an information-seeking dialogue is thus embedded in a critical discussion. Other types of information might be needed at a certain stage of the dialogue, for instance encyclopaedic (see Walton 2006), or terminological information.

The relevance of a shift depends on the purpose of the dialogue in which it occurs and on the shared purposes of the participants in the discussion. In fact, when the participants in a dialogue do not share the same dialogical goals, such as, for instance "getting the best deal" or "reaching an agreement", the risk of irrelevance can arise. The following case is extremely interesting for the explanation of these concepts. We should first notice that the purpose of the discussion is to make a decision, and to achieve this goal an information-seeking dialogue is embedded in it (Walton 2003, p. 41):

\section{Case 3}

Mrs. Francois, a sixty-three year old French Canadian woman diagnosed as suffering from stress incontinence, sustained injuries to her bladder and colon during an operation, and was put on antibiotics. Six days later, when she suffered severe abdominal pain and her blood pressure dropped dramatically, she was transferred to intensive care. A surgeon was consulted, and diagnosed her as suffering from generalized peritonitis [...]. She required immediate surgery. When Mrs. Francois was told that she needed an operation, and that without it she would probably die, she refused to give consent [...]. Her family declared that their mother was behaving "abnormally", and said that they would blame the surgeon for their mother's death if he did not operate.

In this example, we can observe that when the dialogue shifts back to a deliberation, a threat is made showing a conflict of purposes. Mrs. Francois' relatives' goal is to defend their interests, while the physician's goal is to make a sensible treatment decision. The original deliberation is transformed into a negotiation. The threat is irrelevant to the purpose of the deliberation, and the dialogical shift is not accepted by, nor acceptable to the physician. For this reason, the argument from threat is both irrelevant and fallacious. If we analyze the case more in depth, we can notice that the difference in dialogical goals stems from a manipulation by Mrs. Francois' relatives of the physician's purpose. The threat they advance, in fact, can be understood only presupposing that the decision of operating Mrs. Francois depended only on the physician's 
interests, and not on the patient's will. By threatening the physician, Mrs. Francois' relatives take for granted that the whole issue is a matter of conflict of interests and not about reaching the best decision. The manipulation of the dialogical purpose, we can notice, is grounded on the manipulation of the interlocutor's purpose and the definition of the whole issue. This example introduces two topics of pivotal importance for the dialogue-types theory: the notion of argument irrelevance and the clash of dialogical purposes.

\subsection{Dialogical Irrelevance as Manipulation of Communicative Situation}

The principle of dialectical relevance is connected to the purpose of a dialogue. The goal of a dialogue, in its turn, depends on the goals of the participants, and on how the individual goals interact in a dialogue to fulfil a common objective. This important aspect of the individuals' interests and its relevance for the study of dialogue types emerges from the dialogue clashes. With this term we indicate the communicative breakdown generated by two incompatible goals characterizing two different dialogues. A dialogue type, we can observe from the previous section, is defined on the basis of the participants' purposes. For this reason, not only does an interlocutor know his own objective, but also understands the other party's intentions. A party can start a dialogue erroneously attributing its own goals to the interlocutor. One party might think to pursue the objectives of a persuasion dialogue, whereas its opponent has as purpose to get what he wants most. This type of difference in perceived goals reflected upon dialectical contrasts emerges in some types of biased argumentation and in fallacious dialogical shifts. While the second case is much more connected to the notion of relevance, the first is a more restricted phenomenon related to the possibility of a persuasion dialogue.

In (Walton 1991) bias is analyzed as a certain type of expression of a dialectical point of view (see also Walton, 1999c). Bias is distinguished from advocacy on the basis of the interests defended. While a person advocating a viewpoint is disposed to consider the evidence on both sides in a balanced way, a biased person bases his argument on his interests and is not disposed to fairly evaluate the contrast of opinions. We can notice that this distinction lays, in many cases, in a difference of purposes, which in its turn lays in differences in the types of dialogue each party attempts to engage in. Many forms of biased argumentation, in Walton's perspective, can be studied as based on a dialogical shift, namely a dialogical difference. Typical cases of bias can be found in news reports supporting a certain party in a controversy, without presenting the other position's viewpoint. In this case, we can observe, a persuasion dialogue is presented as information-seeking. Walton's concept of bias can be explained using the notion of representation of a communicative situation. Differences in dialogical goals, in other words, can be analyzed as different representations of dialogical and communicative situations. The analysis of the following cases can clarify this concept (Walton 1991, p. 7): 


\section{Case 4}

Pay no attention to those American Tobacco Institute arguments against restrictions on smoking. You shouldn't take their arguments seriously; after all, those arguments are bought and paid for by the tobacco industry.

In this example, we can notice how the circumstantial ad hominem is grounded on a difference in dialogical goals. While the American Tobacco Institute's goal is winning the discussion and defending the interests of the companies it is financed by, the purpose of other party involved in the dialogue is simply clarifying the issue by evaluating proofs. The American Tobacco Institute, in other words, apparently takes for granted the dialogical situation in which the issue needs to be clarified by means of proofs, but in fact is committed to a communicative situation in which the smokers' interests are opposed to the tobacco industry's one.

Circumstantial ad hominem attacks sometimes can be grounded on false or irrelevant accuses of bias, such in the following case, which is useful to show how dialogical purposes and the interlocutors' representation of the communicative situation can be manipulated (Walton 1991, p. 2):

\section{Case 5}

Bob and Wilma are discussing the problem of acid rain. Wilma argues that reports on the extent of the problem are greatly exaggerated and that the costs of action are prohibitive. Bob points out that Wilma is on the board of directors of a U.S. coal company and that therefore her argument should not be taken at face value.

Bob's criticism, which can be interpreted as a circumstantial ad hominem, is an accusation of bias directed against Wilma's dialogical intentions. The strength of Bob's move, which is fallacious given the context of persuasion dialogue, stems from a reasonable principle, namely the conflict of dialogical purposes. Bob accuses Wilma of manipulating the dialogical goal. Bob's move, in other terms, can be understood only interpreting the dialogical situation as manipulated by Wilma. By advancing an ad hominem argument, Bob takes for granted that Wilma's real intention is not that of clarifying the issue by evaluating the evidence, but that of winning the discussion and defending her interests. Being these goals incompatible, Bob presents the dialogue as impossible to continue and the result is a communication breakdown, more than a successful defence of Bob's viewpoint.

From the study of these cases, we can observe how dialogical relevance is grounded on an interlocutor's intentions and recognition of the other party's goals. On the other hand, bias can be described as one party misrepresenting the real and shared communicative goal and 
situation. A close argumentative move is the straw man, in which one party misrepresents the other party's communicative goal and consequently the communicative situation which the other party's move presupposes, as in the following case (Walton and Krabbe 1995, p. 110):

Case 6

Wife: I'll do the cooking if you'll washes the dishes Husband: Why should I?

In this example, the husband shifts the dialogue from a negotiation to a persuasion dialogue, misrepresenting his wife's intention of negotiating a division of tasks. The issue and the purpose of the conversation Wife presupposes is an equal division of tasks, implying a communicative situation in which the two participants have conflicting interests, but equal duties and rights in arranging the dinner. Husband manipulates Wife's dialogical purpose, distorting the whole communicative situation and taking for granted that the duties and rights are not object of negotiation, and therefore not equal between the interlocutors.

The characteristics of dialogical relevance and irrelevance outlined above are helpful to understand the mechanism of fallacious dialogical moves as signs of illicit dialogical shifts. In these cases, an argument pattern brings about a communicative move manifesting precise dialectical intentions, which can be relevant or irrelevant depending on the dialogical framework.

\subsection{Arguments as Sequences in a Dialogue}

Arguments considered to be fallacious in the standard treatment of fallacies are, in Walton's approach, studied as patterns of inference that can be reasonable in certain contexts of dialogue and fallacious in others. As seen in the first section, the acceptability of a move depends on the rules of the dialogue game in which it is performed. The rules regulate the types of admissible moves used to accomplish the purpose of the game, the conditions of fulfilment of the burden of proof, and the possibilities of shifting it on the other party. In (Walton 1988) the analysis of some arguments, traditionally considered fallacious, is connected to the context of dialogue, the common ground, and the burden of proof. In later works, this idea is developed by inquiring into, for instance, the acceptability of circular arguments in witness testimony (Walton 2005), or the reasonableness of ad hominem arguments in examination dialogue (Walton 2006b).

The relevance of argument schemes can also depend on the context of dialogue imposing the conditions of fulfilment of burden of proof. One clear example can be found in some uses of the argument from ignorance (Walton 1996, p. 84): 


\section{Argument from Ignorance}

$\begin{array}{ll}\text { MAJOR } & \text { If } A \text { were true, then } A \text { would be } \\ \text { PREMISE } & \text { known to be true } \\ \text { MINOR } & \text { It is not the case that } A \text { is known to be true. } \\ \text { PREMISE } & \\ \text { CONCLUSION } & \text { Therefore } A \text { is not true. }\end{array}$

This kind of argument can be reasonable in certain types of dialogue, such as deliberation, in which positive evidence is lacking and a choice has to be made. For instance we can consider the following case (Walton 1995, p. 150):

\section{Case 7}

I do not know that there is a skunk in the cabin. Therefore it is false that there is a skunk in the cabin

The lack of positive evidence is taken as a presumptive argument based on negative evidence, in a context in which a decision has to be made. A similar context may be the trial, in which when the prosecution has not proved guilt, it is reasonable to conclude that the accused is not guilty (Walton 1988, p. 238):

\section{Case 8}

Consider a case where the plaintiff claims to have left her dress at a dry cleaning establishment. Despite having lost the receipt for having deposited the dress at the cleaner's, she claims compensation for the loss of the dress. The defendant produces his books, and claims there was no record of his receipt of the dress. In this case, the plaintiff was unable to prove the defendant received the dress, therefore the judge ruled for the defendant. This appears to be an ad ignorantiam argument. But it is a reasonable one, because the burden of proof is on the customer to prove by a receipt that she had deposited the item at the cleaner's. On the other hand, suppose the plaintiff argued that the cleaning proprietor was unable to prove non-delivery of the dress from his records, therefore my contention that I did deliver the dress is justified. This would be a fallacious use of the argumentum ad ignorantiam.

In this example, we should be able to see how the fallaciousness of the argument depends on the specific rules of the dialogue game the participants are involved in, and, in particular, on the rules governing the burden of proof.

Other clear cases of argumentative patterns relevant only in certain dialogue contexts are the ad hominem arguments and the arguments from threat presented above. Since their purpose is to attack the other party and to lead the opponent to make a decision favorable to the speaker, 
they are relevant respectively in a quarrel and in a negotiation. When these arguments are used in a different dialogue type, they are often evaluated as irrelevant. We can for instance consider the following cases (Norman et al. 2003, p. 41; Walton 2000, p. 85):

\section{Case 9}

A major airline hired a new CEO who cuts costs, angering the union, who began to portray him as devil. Union-management negotiations broke down, and the company went bankrupt.

\section{Case 10}

If I cancel my subscription to the German paper, then, the Nazis say, I will be subject to "unfortunate consequences", which would probably include at least severe bodily injury.

In case 9, ad hominem arguments are used in a negotiation. The use of these moves is a sign that the purpose of the union is not the resolution of a conflict of interests in its favor, but simply one of insulting or verbally attacking the opponent. The type of argument employed reveals a shift to a quarrel, which is irrelevant to the goal of the original dialogue. This shift, instead of helping to achieve the purpose of a negotiation, blocks it. Similarly, in case 10, the use of argument from threat is irrelevant in a context of dialogue in which the purpose is to persuade the other party.

Walton's theory of dialogue types is extremely helpful in recognizing irrelevance not only of patterns of argument, but of argumentative moves as well. For instance, persuasive definitions can be considered complex argumentative moves grounded on argument from verbal classification. An example can be "Abortion is the murder of an innocent human being". This kind of argument (see Walton 2003, p. 152) can be reasonable in some cases of persuasion dialogue or in some political speeches, but fallacious when used in a context in which the goal is not to prove a conclusion, but to explain the meaning of a term. In this perspective, a persuasive definition cannot be properly used in a dialogue such as information seeking.

The principle of Walton's dialectical relevance seems to open up interesting perspectives in theoretical studies on dialogue. First, we can observe how dialogical relevance can be developed emphasizing the notions of common ground and empathy. In fact, as seen above, the interlocutors decide to interact in order to achieve a common goal, or a goal that somehow overlaps with the other party's (see Rigotti and Cigada, 2004). The basic feature we want to highlight in our interpretation of Walton's dialogue types is that the interlocutors, in order to successfully interact, must understand the purpose, desires, and intentions of the other party. Another fundamental aspect is that the study of Walton's dialogue types leads towards a deeper analysis of the interlocutors' roles and conversational contexts. A strong suggestion in this direction comes from the analysis of case 6: the fallaciousness of the 
argument from ignorance depends on the legal system the interlocutors are dealing with. Similarly, the study of arguments from threat and other patterns of proof suggest the possibility of a plurality of dialogues dependent not only on the general goal of the discussion, but also on the interlocutors' roles (see Walton 2003, p. 194). These observations will be developed in the next section.

\section{Dialectical relevance in dialogue contexts: A communicative model of dialogue}

Common ground, conversational and institutional context, and the fundamental role of participants' communicative purposes are pivotal elements in the development of dialogue type theory into a communicative approach to dialogical argumentation in which intersubjectivity plays a fundamental role. This account is highlighted in Walton's work on dialogue types (1998, p. 102), in which the necessity of considering empathy in negotiation is explicitly acknowledged. In fact, in negotiation, such as in other kinds of dialogues analyzed in (Walton 2006), we notice that it is necessary to understand the hearer's purposes and knowledge, in order for the conversational exchange to be successful. In this section, we will present the basic points of a contextual model of dialogue types, stemming from an interpretation and development of Walton's latter accounts of his dialogical theory.

\subsection{Dialogues as Interactions in a Context}

In his study on ethical argumentation (2003), Walton analyzed the theme of dialectical relevance and its relation to conditions of ethical justification and persuasive use of definition. The problem of analyzing relevance in relation to a field of arguments, such as arguments stemming from ethics, cannot be solved only by adopting the broad classification of dialogues presented in (Walton and Krabbe 1995). The difference in force and typology of ethical arguments depends, in fact, on the contextual institution characterizing the dialogue in which they are used. The contextualization of a dialogue in its institutional background influences, in its turn, the structure of the type of dialogue it represents. For this reason, Walton noticed the possibility of having several kinds of persuasion dialogue, or negotiation (see Walton 2000, p. 186), defined on the basis of the context in which they are placed. In case of persuasion dialogues, for instance, the purposes and commitment rules of an intellectual discussion are different from the goals and norms of a legal trial (Walton 2003, p. 195). In the first case, winning or losing is not as relevant as having a good discussion; in the second case, on the contrary, the discussion has to be resolved by determining a winner. While the general goal of the two persuasion dialogues is the same, namely to resolve or clarify an issue, the precise interests of the participants are noticeably different. Thus, the commitment rules and the conditions of relevance cannot be the same. The same argument from ignorance which 
is legitimate in a trial, may be only a weak or even irrelevant type of proof in an intellectual dialogue. Moreover, the evaluation of ethical argumentation and verbal disputes about definitions of some ethical terms involves a strong emphasis on the notion of common ground. Some definitions, considered fallacious in some contexts of conversation, are reasonable and acceptable paraphrases when the hearer agrees on the speaker's values and terminology. These two aspects of Walton's dialectical system, namely the importance of the interlocutor's roles and their shared knowledge, are developed in his recent studies on legal argumentation (Walton 2006, 2007).

In (Walton 2006) the interlocutors' position and the notion of empathy are studied in relation to the analysis of information-seeking dialogue and explanation. For instance, in the framework of a dialogue aimed at explaining a concept, such as some kinds of informationseeking dialogues, simulative reasoning is fundamental in order for a speaker to successfully achieve his communicative goal of making the concept clearer to the interlocutor (p. 203). An explanation achieves its goal, in fact, when the interlocutor's understanding of the topic treated is increased. For this reason, one crucial aspect of the communication success is the assessment of the difference of knowledge. The speaker, in other words, should be empathic with the hearer; in this case, he should understand his common ground and adapt the communication to his background.

If we further develop this insight, we can observe that proper evaluation of the discussion is not only dependent on the dialogue type, but on the broader notion of interactional context, including as a fundamental factor the relation between interlocutors Walton highlighted (see pp. 211-212; for the notion of communicative context, see Rigotti 2007; Rigotti and Rocci, to appear). With "communicative context" we intend the set of factors intervening in the communicative event such as the interlocutors, the interlocutors' goals, the communicative situation (or communicative interpersonal positions), and the common knowledge. For instance, the success requirements of a scientist-scientist explanation are different in nature from the rules and the type of an explanatory interaction between a scientist and a layperson. In the first case, the interlocutors are on the same interactional level and share the same knowledge. In the second case, not only is the interlocutors' background different, but their positions and roles also differ, that is, the communicative situation is different. The institutional context and the common ground of the participants differently characterize the two dialogues.

In Walton's recent studies on dialogue and context, it is possible to notice a progressive broadening of the concept of dialogue type. The conversational setting and the agents' subjectivities play an increasingly important role in argument evaluation. In the following subsection all the suggestions highlighted in Walton's studies on dialogical relevance will be integrated in a model of dialogue. 


\subsection{Extending the Dialogical Framework}

In the previous sections, we focussed on the process which leads from dialogue games to a wider theory of dialogue contexts. In this concluding part of the paper we will summarize the insights presented above and integrate them into the idea of a communicative context of dialogue.

Following (Rigotti and Cigada 2004), we can represent the dialogical components of a dialogical context emerging from Walton's studies as below:

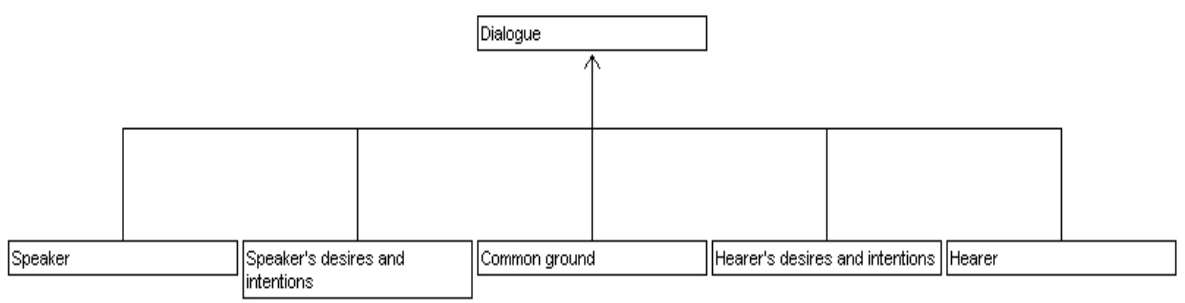

Figure 6: Components of Dialogue Context

The structure of a dialogue, in this diagram, is represented as constituted by a speaker, a hearer, common knowledge, and the interlocutors' intentions. These factors constitute the essential criteria for the evaluation of a specific dialogue according to the principle of dialogical relevance. This model can be further developed to include other communicative aspects highlighted by Walton (see also Walton and Macagno, to appear). For instance, as seen in the sections above, dialogical rules depend on the institutional setting the conversation is set in. A persuasion dialogue between teacher and pupil follows rules different from a discussion between mother and son, or between two scientists. The interaction roles impose certain constraints on the moves that are allowed. For instance, the following threat can be relevant in certain forms of negotiation between mother and son, but cannot be admitted in a teacher-pupil dialogue:

\section{Case 11}

Do your homework or no video-games for a week!

The relationship between the interlocutors, in this case, is essential for deciding whether an argument is relevant or not. Two important levels of context analysis should be included: the obligations stemming from the roles in the interrelation, and the social and communicative rules of the community. We can represent the first level as a set of conditions that should be fulfilled in order for the communication to be successful (see also Rigotti \& Cigada, 2004): 

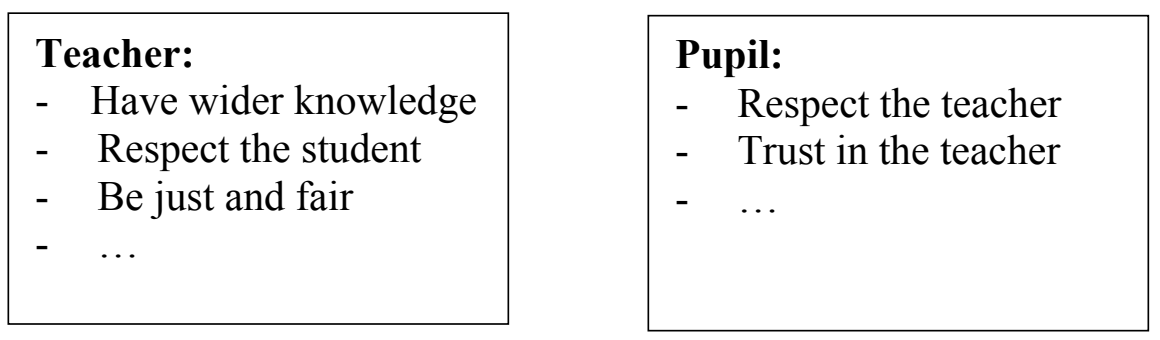

Figure 7: Interpersonal dialogical requirements of case 12

These requirements can be combined with the community rules of interaction. In present-day Western culture, for example, threats should be prudential and should never give rise to an escalation leading to physical violence. In other cultures or communities, a more severe type of threat might be legitimate. For instance, in Europe at the beginning of the last century teachers were allowed to use threat appeals in which escalation to violence was common.

Taking these cases into consideration, we can notice that the traditional normative dialectical models cannot provide adequate instruments to decide whether the arguments used are fallacious or not. The communicative framework, therefore, should be broadened to include factors that go beyond simple dialectical rules. Interpreting the dialogue as a communicative model constituted by human agents, and not by abstract entities, allows one to expand dialectical theory to include fundamental contextual elements of human communication.

The link between Walton's dialogue theory and linguistic approaches to communication may play an important role in the development of dialogue theory. Conceiving dialogues as human interactions, characterized by the agents' goals, can lead to integrating into the analysis of arguments factors such as desires, emotions, and values, that is, elements directing human choices. Moreover, analyzing dialogical moves in terms of relevance in a precise conversational context allows one to evaluate the acceptability of an argument in relation to its ability to fulfil its function as a sequence in a dialogue. A dialogue theory interpreted in a framework extended to "dialogical context" has the pivotal advantage of joining together the dialectical tools of argument evaluation and the linguistic instruments of textual analysis. In this fashion, does not only an argument represent the possible instantiation of a reasoning pattern supporting a conclusion, but also a textual sequence of a real dialogue between human actors in a given culture.

\section{Conclusions}

The evolution of dialogue games into a theory of dialectical relevance shows how notions of dialogue and relevance have evolved in relation to 
communicative factors taken into consideration. The model of dialogue types is one of Walton's most interesting proposals and offers several possible applications. This paper has focused on the development of argumentation schemes and dialogue embeddings in the study of fallacies. The first section offered an overview on the approaches to dialogue games in Walton's account. The dialectical models present the application of formal abstract theories to descriptive cases. After explaining Walton's types of dialogue, the paper took into consideration principle of dialectical relevance, used to apply the different dialogical contexts to the study of fallacies. Dialectical relevance, in fact, allows one to describe fallacies and illicit argumentative moves in dialectical terms, for instance biased argumentation, threat appeals, and straw man. With the progressive improvement of the notion of dialectical relevance, abstract model of dialogue types were extended, including elements such as contextual setting and interlocutors' relation. We can articulate the proposals suggested in several of Walton's works in a dialogue model, in which argumentation theory combines with a linguistic approach to communication. Arguments, in this fashion, can be analyzed not only as dialectical moves used to support a conclusion, but also as textual sequences, which must fulfil precise constraints stemming from their function in a complex communicative event.

\section{References}

Barth, Else \& Erik Krabbe (1982). From Axiom to Dialogue: A Philosophical Study of Logics and Argumentation. Berlin: Walter de Gruyter.

Eemeren, Frans H. van \& Rob Grootendorst (2004). A Systematic Theory of Argumentation. Cambridge: Cambridge University Press.

Eemeren, Frans H. van \& Peter Houtlosser (2005). Theoretical Construction and Argumentative Reality: An Analytic Model of Critical Discussion and Conventionalised Types of Argumentative Activity. In David Hitchcock (ed.), The Uses of Argument: Proceedings of a conference at McMaster University, 18-21 May 2005. Ontario Society for the Study of Argumentation.

Gatti, Maria Cristina (2000). La Negazione tra Semantica e Pragmatica. Milano: ISU.

Hamblin, Charles. L. (1970). Fallacies, London, UK: Methuen.

Hintikka, Jaakko (1979). Information-Seeking Dialogues: A Model. Erkenntis 38: 355368

Krabbe, Erik (1999). Profiles of Dialogue. In Jelle Gerbrandy, Maarten Marx, Maarten de Rijke, and Yde Venema (eds.), JFAK: Essays Dedicated to Johan van Benthem on the Occasion of his 50th Birthday III, Amsterdam: Amsterdam University Press (Vossiuspers; also on CD-ROM), pp. 25-36.

Krabbe Erik (2001). The Problem of Retraction in Critical Discussion. In: Christopher W. Tindale, Hans V. Hansen, and Elmar Sveda (eds.), Argumentation at the Century's Turn (CD-ROM), ISBN 0-9683461-1-1 (Proceedings from the Conference of The Ontario Society for the Study of Argumentation, May 13-15, 1999, Brock University, St. Catharines, Ontario).

Norman, Timothy, Daniela Cambogim, ERIK Krabbe \& Douglas Walton (2003). Argument in Multi-Agent Systems. In Chris Reed and Timothy Norman (eds.), Argumentation Machines: New Frontiers in Argument and Computation. Amsterdam: Kluwer, pp. 15-54 
Prakken, Henry (2001). Modelling Defeasibility in Law: Logic or Procedure? Fundamenta Informaticae 48: 253-271

Rigotti, Eddo \& Cigada Sara (2004). La comunicazione verbale. Milano: Apogeo.

Rigotti, Eddo (to appear). Towards a typology of manipulative processes. In L. de Saussure, P.Schulz (eds), New Perspectives on Manipulation and Ideologies: Theoretical Aspects, Amsterdam: John Benjamins.

Rigotti, Eddo (2007). Relevance of Context-Bound Loci to Topical Potential in the Argumentation Stage. Argumentation 22: 519-531.

Rigotti, Eddo \& Rocci, Andrea (2006). Tema-rema e Connettivo. In Giovanni Gobber, Maria Cristina Gatti \& Sara Cigada, S_ndesmoi. Connettivi nella realtà dei testi, Milano: Vita e Pensiero, pp. 3-44.

Rigotti, Eddo \& Rocci, Andrea (to appear). Argument from context. For an overview on the topic, see www.epicentre.com.unisi.ch/pages/slides rigotti rocci.pdf

Seuren, P.A.M. (2000), Presupposition, Negation, and Trivalence. Journal of Linguistics 36: 261-297

Walton, Douglas \& Krabbe, Erik C. W. (1995). Commitment in Dialogue. Albany: State University of New York Press.

Walton, Douglas (1984). Logical Dialogue Games and Fallacies. Lanham: University Press of America.

Walton, Douglas (1988). Burden of Proof. Argumentation 2: 233-254.

Walton, Douglas (1989). Informal Logic. New York: Cambridge University Press.

Walton, Douglas (1991). Bias, Critical Doubt and Fallacies. Argumentation and Advocacy 28: $1-22$

Walton, Douglas (1992). Types of Dialogue, Dialectical Shifts and Fallacies. In Frans H. van Eemeren wt al. (eds.), Argumentation Illuminated, Amsterdam, SICSAT: 133-147.

Walton, Douglas (1995). A Pragmatic Theory of Fallacy. Tuscaloosa and London: The University of Alabama Press.

Walton, Douglas (1996). Arguments from Ignorance, University Park: The Pennsylvania University Press.

Walton, Douglas (1997). Appeal to Expert Opinion. University Park: The Pennsylvania State University Press.

Walton, Douglas (1998). The New Dialectic. Conversational Contexts of Argument. University of Toronto Press, Toronto.

Walton, Douglas (1998a). Ad Hominem Arguments. Tuscaloosa: The University of Alabama Press.

Walton, Douglas (1999). One-Sided Arguments. A Dialectical Analysis of Bias. State University of New York Press, Albany.

Walton, Douglas (1999a). Profiles of Dialogue for Evaluating Arguments from Ignorance. Argumentation 13: 53-71

Walton, Douglas (1999b). Slippery Slope Arguments, Newport News: Vale Press.

Walton, Douglas (1999c). One-Sided Arguments. A Dialectical Analysis of Bias. Albany: State University of New York Press.

Walton, Douglas, (2000). Scare Tactics. Dordrecht, Holland: Kluwer.

Walton, Douglas (2003). Ethical Argumentation. Lanham: Lexington Books

Walton, Douglas (2003a). The Interrogation as a Type of Dialogue. Journal of Pragmatics 35: 1771-1802

Douglas Walton (2005). Begging the Question in Arguments Based on Testimony. Argumentation, 19: 85-113.

Walton, Douglas (2006). Argumentation Methods for Artificial Intelligence in Law. Springer, in press

Walton, Douglas (2006a). Fundamentals of Critical Argumentation. New York: Cambridge University Press.

Walton, Douglas (2006b). Examination dialogue: An Argumentation Framework for Critically Questioning an Expert Opinion. Journal of Pragmatics 38: 745-777

Walton, Douglas (2007). Character Evidence: An Abductive Theory. Berlin, Springer.

Walton, Douglas \& Fabrizio Macagno (2005). Common Knowledge in Argumentation. Studies in Communication Sciences 5(2): 1-22 


\section{Fabrizio Macagno}

Walton, Douglas \& Fabrizio Macagno (to appear). The Fallaciousness of Threats: Character and Ad Baculum. Submitted to Argumentation.

Wells, Simon \& Chris Reed (2006). Knowing when to Bargain: The Roles of Negotiation and Persuasion in Dialogue. In Floriana Grasso, Rodger Kibble \& Chris Reed (eds.), Proceedings of the CMNA Conference. Riva del Garda, Italy: 83-88 